\title{
A reflexividade como elemento de mediação - O caso de Francisco Milanez
}

\section{BRUNO DE SOUZA LESSA ${ }^{1}$ \\ FERNANDO DIAS LOPES ${ }^{2}$ Célia Elizabete Caregnato ${ }^{3}$}

\author{
1 Universidade de Fortaleza (UNIFOR) / Programa de Pós-graduaÇão EM AdMINISTRAÇÃo - ForTALEZA - CE, BRASIL

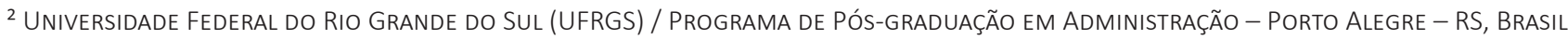

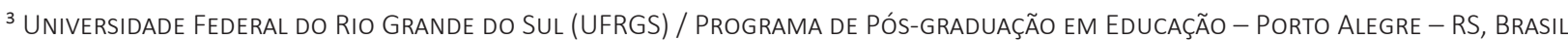

\begin{abstract}
Resumo
Este artigo teve como objetivo debater a forma como o conceito de reflexividade é concebido por Pierre Bourdieu, e como se desenvolve e influencia a sociologia, no nível dos indivíduos, de Bernard Lahire. Para operacionalizar a forma como o conceito é trabalhado pelos autores, porém enfatizando seu desenvolvimento por Lahire, esse trabalho apresenta como caso empírico o desenvolvimento da reflexividade na trajetória biográfica de José Francisco Bernardes Milanez, ativista histórico do movimento ambiental do estado brasileiro do Rio Grande do Sul. O argumento central que defendemos é que o conceito de reflexividade de inspiração bourdieusiana tem um determinado peso objetivista e estruturalista, o qual secundariza a capacidade de reflexão e agência dos indivíduos, porém apesar desse peso, no âmbito da vida social dos atores a reflexividade atua como elemento mediador entre estruturas e agência individual. Nesse sentido, as capacidades reflexivas podem ser melhor entendidas e analisadas se forem consideradas as maneiras como os indivíduos articulam dialética e concomitantemente suas práticas cotidianas e seus processos reflexivos. Enfatiza-se tanto na escrita deste artigo, quanto nas suas conclusões, que as análises sociológicas no nível dos indivíduos podem ser potencialmente mais substantivas ao considerarem estrutura, agência e reflexividade de forma integrada, algo que a associação de elementos conceituais e argumentativos específicos desses dois autores centralmente destacados habilita, evitando, assim, falsas antinomias.
\end{abstract}

Palavras-chave: Reflexividade. Bourdieu. Lahire. Agapan. Brasil.

\section{Reflexivity as a mediating element - The case of Francisco Milanez}

\begin{abstract}
This article aimed to discuss how Pierre Bourdieu's concept of reflexivity was conceived, and how it influenced and was developed by Bernard Lahire's in his sociology. To operationalize the way the concept is articulated, but emphasizing its development by Lahire, this paper presents as an empirical case how reflexivity was engendered in José Francisco Bernardes Milanez' biographical trajectory, a historical environmental activist from the Brazilian state of Rio Grande do Sul. The central argument we defend is that the Bourdieusian-inspired concept of reflexivity has a certain objectivist and structuralist weight, which gives a secondary role to individuals' reflection capacity and agency. Despite this weight, reflexivity acts as a mediator between structures and their individual agency within actors' social lives. In this sense, reflexive capacities can be better understood and analyzed by considering the ways individuals connect their daily practices, dialectically and concomitantly, with reflexive processes. This article emphasizes that sociological analyses at the individual level can be potentially more substantive if they consider structure, agency, and reflexivity in an integrated way. Finally, we argue that the conceptual and argumentative association of elements from the two authors helps to avoid false antinomies.
\end{abstract}

Keywords: Reflexivity. Bourdieu. Lahire. Agapan. Brazil.

\section{La reflexividad como elemento de mediación - El caso de Francisco Milanez}

\section{Resumen}

El objetivo de este artículo es discutir cómo el concepto de reflexividad es concebido por Pierre Bourdieu, y cómo la sociología de Bernard Lahire se desarrolla e influye a nivel de los individuos. Con el fin de operacionalizar la forma en que los autores trabajan el concepto, pero enfatizando su desarrollo por Lahire, este trabajo presenta como caso empírico el desarrollo de la reflexividad en la trayectoria biográfica de José Francisco Bernardes Milanez, activista histórico del movimiento ambientalista del estado brasileño de Río Grande do Sul. El argumento central que defendemos es que el concepto de reflexividad de inspiración bourdieusiana tiene un cierto peso objetivista y estructuralista, que relega la capacidad de reflexión y agencia de los individuos pero, a pesar de este peso, en el ámbito de la vida social de los actores la reflexividad actúa como elemento mediador entre las estructuras y la agencia individual. En este sentido, las capacidades reflexivas pueden entenderse y analizarse mejor si se consideran las formas en que los individuos articulan la dialéctica y, concomitantemente, sus prácticas diarias y procesos reflexivos. Tanto en el desarrollo de este artículo como en sus conclusiones se destaca que los análisis sociológicos a nivel de los individuos pueden ser potencialmente más sustanciales al considerar la estructura, la agencia y la reflexividad de manera integrada, algo que la asociación de elementos conceptuales y argumentales específicos de esos dos autores centralmente destacados permite, evitando así falsas antinomias.

Palabras clave: Reflexividad. Bourdieu. Lahire. Agapan. Brasil. 


\section{INTRODUÇÃO}

Este artigo tem por objetivo examinar as potencialidades analíticas dos aparatos conceituais de Pierre Bourdieu e Bernard Lahire para compreender o papel da reflexividade nas trajetórias individuais. Na medida que esses aparelhos foram sendo gradualmente agrupados, seus potenciais para compreender questões relativas à subjetividade dos atores sociais tornou-se mais claro, especialmente em relação aos processos reflexivos que os indivíduos articulam para dar coesão a suas ações ao longo das diferentes relações que constroem em suas vidas sociais.

Ao reconhecer esse potencial analítico, bem como ao problematizar a aproximação entre estes dois autores e suas contribuições epistemo-teórico-metodológicas, introduzimos o estudo de parte da trajetória biográfica de Francisco Milanez. Francisco é um ambientalista histórico brasileiro e membro da Associação Gaúcha de Proteção ao Ambiente Natural (Agapan¹), uma das mais antigas da América Latina. Além de sua participação na Agapan, Francisco também tem sido militante em muitas iniciativas no campo da educação e da proteção ambiental, causas as quais tem defendido durante décadas e desenvolvido diferentes linhas de ação.

No entanto, é necessário destacar que este trabalho não se concentra na descrição da vida de Francisco, mas na análise de sua trajetória através da lente teórica Bourdieusiana-Lahireana. Para atingir tal objetivo, ele articula dois movimentos principais. $O$ primeiro remonta as sociologias de Bourdieu e Lahire e enfatiza o papel da reflexividade nesses autores, ressaltando sua ênfase epistêmica. Além disso, neste segmento epistemo-teórico, sublinhamos criticamente tanto a faceta neo-objetivista quanto o peso das estruturas nas construções teóricas bourdieusianas (Alves, 2016; Correa, 2015; Peters, 2013), que reverberam nas contribuições de Bernard Lahire (Caetano, 2011, 2012, 2013; Vandenberghe, 2013).

Neste sentido, argumentamos que, por um lado, Bourdieu apresenta o habitus como um sistema de disposições estruturadas e estruturantes de percepção, valorização e ação construído e corporificado em um contexto social e histórico particular (Bourdieu, 2007). Por outro lado, em Lahire, esta ideia subjacente de um passado que foi incorporado através de processos de socialização permanece em grande parte. Embora o segundo autor divirja da noção de que o habitus conferiria unidade às práticas dos atores sociais, as estruturas incorporadas no passado continuam a se atualizar no presente e acabam ainda condicionando as práticas de acordo com o quadro contextual em que operam.

No entanto, Lahire $(1997,2002,2004)$ defende que o passado encarnado não seria unificado por características como classe econômica ou profissão. Dessa forma, o habitus surgiria como um estoque de disposições heterogêneas construídas no curso de distintos processos de socialização. Portanto, Lahire realmente consegue preencher uma lacuna no edifício teórico de Bourdieu no que diz respeito à pluralidade de socializações e sua incorporação dentro dos indivíduos, mas as estruturas encarnadas se atualizam e impactam as possibilidades de reflexividade dos indivíduos.

Em seguida, o segundo movimento apresenta, através da análise da biografia sociológica de Milanez, as elucubrações expostas no primeiro momento, empregando os aparatos conceituais dos autores na análise de parte da trajetória social de Francisco Milanez. Metodologicamente, recorremos à construção de uma biografia sociológica para empregar os elementos conceituais que nos permitiram analisar sua trajetória social (Coutinho, 2015; Elias, 1995; Lahire, 2010; Setton, 2015). As análises e interpretações aqui apresentadas só foram possíveis devido aos relatos orais, escritos e documentos fornecidos pelo próprio Francisco durante um processo de pesquisa que durou aproximadamente dois anos. Neste sentido, contando com as perspectivas estruturais e construtivas de Bourdieu e Lahire, realizamos uma análise interpretativa, que adota uma postura dialética inerente, no sentido de explorar as contradições que permitem os processos reflexivos pelos quais o ator biografado passou ao longo de sua trajetória social.

A fim de atingir seus objetivos, este artigo está estruturado da seguinte forma. Após esta introdução, a segunda seção fornece uma contextualização concisa do esforço sociológico de Pierre Bourdieu. A terceira seção explica então as contribuições teóricas deste autor, concentrando-se na apresentação de como o conceito de habitus se enquadra em seu edifício epistemológico. Em seguida, a quarta e quinta seções introduzem a maneira como a noção de reflexividade é fomentada e gerada dentro da sociologia de Bourdieu. Depois disso, a sexta seção desenvolve como Bernard Lahire refletiu sobre os

\footnotetext{
${ }^{1}$ A associação é uma das primeiras organizações no Brasil a participar da luta pela causa ambiental, tendo sido fundada em abril de 1971. A associação foi pioneira, por exemplo, nas lutas pelo avanço da agroecologia, bem como na defesa da Amazônia e da Mata Atlântica. Também produziu a primeira lei brasileira contra os agrotóxicos, em 1982. Recuperado de http://www.fao.org/family-farming/network/network-detail/en/c/170832/. Informações mais completas sobre ela também podem ser encontradas em: http://www.agapan.org.br/
} 
conceitos Bourdieusianos e os avanços sugerido para eles. A próxima seção introduz os procedimentos metodológicos subjacentes à operacionalização deste trabalho. A oitava, por sua vez, examina a trajetória social de Francisco Milanez, empregando as reflexões e conceitos baseados nas lentes teóricas Bourdieusianas-Lahireanas apresentadas. Por fim, a última seção oferece nossas considerações finais.

\section{A TENTATIVA DE RESOLVER CONTROVÉRSIAS FUNDAMENTAIS}

Os esforços de pesquisa de Bourdieu visavam mitigar, se não resolver, algumas das principais antinomias que sustentavam as Ciências Sociais em seus dias, a saber, estrutura versus agência, objetivismo versus subjetivismo ou trabalho teórico versus empírico (Alves, 2016; Caetano, 2011, 2013; Peters, 2013, 2017; Vandenberghe, 2013). Neste sentido, Wacquant (1992) enfatiza que Bourdieu estava preocupado principalmente com os dois primeiros, uma vez que eles implicavam em dois erros graves.

Por um lado, Bourdieu criticou os estudiosos que seguiam uma visão excessivamente estrutural e objetivista, descrevendo os agentes sociais como portadores de estruturas que se encaixariam mecânica e irrefletidamente dentro desses agentes. Essas relações históricas objetiváveis, ou seja, as estruturas, existiam como uma forma imperiosa, reificada e hipostasiada para esses estudiosos criticados, que empurravam tais estruturas para dentro dos agentes, fazendo-os agir de acordo com uma certa conduta anterior assumida. Por exemplo, agentes pertencentes a uma determinada estrutura de classe exibiriam práticas num padrão esperado para aquela classe, fosse ela burguesa ou proletária (Alves, 2016; Bourdieu \& Wacquant, 1992; Peters, 2013, 2017a; Vandenberghe, 2013).

Por outro lado, Bourdieu formulou uma crítica sólida ao erro subjetivista, que era conceder plena racionalidade, reflexividade e agência aos agentes do mundo social, desconsiderando as relações sociais historicamente incorporadas, bem como os espaços onde tais interações ocorrem. Em outras palavras, o erro subjetivista negligenciou (ou mesmo ignorou) a transmutação da organização social, da história e das posições sociais nos esquemas mentais de apreciação, avaliação e ação dos indivíduos. Assim, dotados de total racionalidade, os agentes seriam capazes de legislar sobre e realizar plenamente suas escolhas (Bourdieu \& Wacquant, 1992; Lahire, 2004, 2005).

Voltando à terceira controvérsia, ou seja, a divisão entre trabalho teórico e empírico, a crítica bourdieusiana afirmou que tal separação seria falaciosa. A migração de Bourdieu da Filosofia para a Sociologia, assim como a condução de suas pesquisas etnográficas na Argélia e Bearn consolidaram a prerrogativa de realizar momentos teóricos e empíricos na epistemologia de Bourdieu. Além disso, ele chegou a uma conclusão semelhante considerando a existência de instâncias objetivistas e subjetivistas na realização de pesquisas sociais, ou seja, essas instâncias seriam inseparáveis umas das outras (Bourdieu \& Wacquant, 1992; Peters, 2017b).

A solução de Bourdieu se baseou no racionalismo científico de Gaston Bachelard, vinculando-o à perspectiva relacional do mundo social de Ernst Cassirer (Bourdieu \& Wacquant, 1992; Peters, 2013, 2017b). Portanto, as diferentes instâncias e níveis de realidade não poderiam ser pensadas casuisticamente de maneira oportuna e seria imperativo produzir pesquisas teóricas e empíricas em relação à realidade. O habitus é a criação teórica deste esforço epistemológico.

\section{O HABITUS COMO INSTRUMENTO DE MEDIAÇÃO}

O habitus é fundamental para compreender o papel das práticas na teoria bourdieusiana, na medida em que permite unificar estrutura e agência, bem como objetivismo e subjetivismo. Este princípio gerador de práticas é construído (e constrói) sobre uma cadeia de mediações e gera uma multiplicidade de ações nos espaços sociais através da consolidação de esquemas de percepção e avaliação. Assim, Bourdieu dá um salto conceitual em direção a uma sociologia de possibilidades perceptivas e cognitivas que ainda situa os agentes em posições estruturalmente situadas. Além disso, o autor francês faz com que os corpos dos agentes influenciem suas práticas objetivadas e sejam sinais de interação obrigatória entre indivíduos e espaços sociais para engendrar tais práticas (Alves, 2016; Bourdieu \& Wacquant, 1992; Caetano, 2011, 2013; Correa, 2015; Peters, 2013, 2017a; Vandenberghe, 2013). 
A variabilidade resultante das diferenças entre os contextos sócio-históricos e as diferentes posições que os agentes ocupam exercem uma restrição estrutural sobre as representações dos indivíduos (Peters, 2013, 2017b). Tal variabilidade é o primeiro sinal dos processos reflexivos que mostram que o habitus não é um conceito estático. A construção dos elementos constituintes do habitus e do mundo social são essenciais para a pesquisa, e é por isso que a investigação da sociogênese das disposições práticas e esquemas interpretativos (assim como do campo em que interagem) demonstra que eles estão relacionados entre si.

Além disso, o suposto subjetivismo e objetivismo antinômico ou entre agência e estrutura são inseparáveis no conceito de habitus. Sendo história incorporada, o hábito nunca deixa de ser atualizado, trazendo consigo elementos de continuidade sócio-histórica e novas experiências da época contemporânea (Alves, 2016; Caetano, 2011, 2013; Correa, 2015). Ademais, a articulação entre as dimensões macro e microssociológicas se dá através de uma sociologia relacional engendrada simultaneamente nas esferas teórica e empírica.

Entretanto, Peters $(2013)$ e Caetano $(2011,2013)$ destacaram inteligentemente que, para Bourdieu, o passado embutido pode ter um peso esmagador sobre as práticas dos indivíduos, uma vez que eles estão ontologicamente articulados com um campo específico. Mesmo que Bourdieu se desvie do objetivismo levi-straussiano ou althusseriano, ele incide em uma espécie de neo-objetivismo expresso pela pressão das estruturas incorporadas no habitus (Peters, 2013). Além disso, quando analisadas em nível individual, as situações vivenciadas pelos agentes se tornam elementos ativadores dessas estruturas incorporadas, deixando assim um espaço limitado para capacidades reflexivas (Caetano, 2011, 2012, 2013).

\section{REFLEXIVIDADE COM E CONTRA SI MESMA}

Bourdieu advertiu que todos os indivíduos estão vinculados às suposições condicionantes relacionadas à sua posição estrutural. A este respeito, é essencial empregar métodos de análise contra nós mesmos para escapar das armadilhas epistêmicas ligadas ao nosso inconsciente condicionado e tais processos, diferentes dos que estamos acostumados, a reflexividade caberia a todos, especialmente aos cientistas sociais (Bourdieu \& Wacquant, 1992).

Para realizar esta volta reflexiva, Bourdieu propõe três movimentos. Primeiro, as condições sociais de produção do sujeito objetivado devem ser objetivadas, assim, o agente é delineado do ponto de vista de uma classe, de um gênero e dos interesses que tendem a se conectar com ele. Segundo, a análise reflexiva se volta para a dimensão institucional, ou seja, o campo em que o indivíduo se encontra; este momento vincula o agente à posição relativa que ele ocupa no mundo social, integrando macro e microcosmos. Terceiro, o pesquisador visa a si mesmo, num processo chamado de objetivação participante, para descobrir os esquemas mentais que o levam a observar o universo em que se encontra (Bourdieu, 2004a, 2004b; Bourdieu \& Wacquant, 1992).

Esta volta reflexiva é seminal já que os agentes sociais estão imersos em uma parcialidade idiossincrática do mundo vivido, e é função do cientista construir as estruturas virtuais que revelam as condições de possibilidade para estes microcosmos. A centralidade desta reviravolta reflexiva depende também da lembrança do cientista de sua própria trajetória social e de sua posição no campo, na medida em que é então que ele pode se encontrar sujeito às condições que atribui aos outros (Bourdieu, 2004b). Ao seguir estes procedimentos, Bourdieu usa a autoridade da ciência como a principal alternativa para reconhecer as condições que pesam sobre os agentes. Além disso, os graus de liberdade de ação são considerados baseados no reconhecimento de determinadas estruturas sociais, e é a posição projetiva do cientista social que pode dar significado objetivo às práticas dos agentes (Correa, 2015; Peters, 2017a).

Portanto, Bourdieu acentua o papel privilegiado das ciências sociais e sua proeminência na análise das realidades. Embora no nível das interações os agentes possam acreditar que são seres reflexivos, na verdade, quando pensam em si mesmos e em suas condições, suas reflexões tendem a ser atraídas de volta a condicionamentos estruturais e simbólicos implícitos a sua posição no espaço social (Bourdieu \& Wacquant, 1992). Sem o trabalho científico e sua volta reflexiva, a reflexividade propriamente dita se torna vinculada aos condicionamentos sociais objetivos que se pretendiam revelar a princípio (Bourdieu, 2004a, 2004b; Bourdieu \& Wacquant, 1992; Correa, 2015; Peters, 2017a). 


\section{O PESO DO MUNDO OBJETIVO}

Com relação à densidade do objetivismo na obra de Bourdieu, Peters (2013) argumenta que, para o autor francês, o ator individual não teria um poder causal autônomo para transformar os pilares que sustentam o espaço social. Segundo Crossley (2001), a raridade dos grandes eventos que poderiam dar origem à reflexividade também coloca em cheque a visão de Bourdieu sobre o agente social. Neste sentido, embora seja verdade que os indivíduos não são dotados de total racionalidade, assim como não podem agir no mundo social independentemente das estruturas relacionais históricas, também não é empiricamente possível afirmar que os processos reflexivos individuais só podem ocorrer em situações esmagadoramente problemáticas.

A este respeito, tanto Peters $(2013)$ quanto Caetano $(2011,2013)$ argumentam que, para Bourdieu, não há apenas uma precedência metodológica, mas também ontológica da objetividade sobre o elemento subjetivo da realidade social. Esta concepção está presente em Bourdieu enquanto ele afirma que seria apenas na quebra da cumplicidade ontológica entre estruturas e disposições (o efeito histerese) que os agentes seriam capazes de resoluções reflexivas (Bourdieu, 1989). Dessa forma, o processo inverso no qual o exercício consciente da reflexividade poderia levar o ator social a romper parcial ou totalmente com tal cumplicidade ontológica é negado.

Entretanto, aproximando Lahire de Bourdieu, Caetano $(2012,2011,2013)$ enfatiza que, embora Lahire afirme que os múltiplos processos de socialização a que os indivíduos são submetidos os obrigam a um maior número de situações potencialmente reflexivas, em nenhum dos autores a reflexividade dos atores sociais seria o foco de uma agenda de pesquisa. Em um grau menor, Lahire acaba reproduzindo o esquema objetivista bourdieusiano na medida em que o estoque de disposições dentro do ator plural de Lahire continua a ser ativado por estímulos vindos de estruturas contextuais. A pluralidade e heterogeneidade de disposições e contextos são de fato muito mais patentes para Lahire do que para Bourdieu, mas o passado incorporado (no habitus) e o mundo objetivo (nos contextos) ainda carregam uma influência inegável sobre as capacidades reflexivas dos indivíduos na sociologia lahireana.

\section{REFLEXIVIDADE PARA BERNARD LAHIRE - CONCEITOS E POSSIBILIDADES}

Embora as disposições individuais estejam entrelaçadas e construídas sobre socializações passadas, elas também são expostas aos processos de mudança social inerentes às sociedades. Os indivíduos podem ser reflexivos na medida em que são capazes de pensar em si mesmos e em suas condições no mundo social. Na teoria disposicionalista bourdieusiana-lahireana, a reflexividade está diretamente relacionada às condições sociais de possibilidade externas aos indivíduos. Sendo assim, há uma pressão do mundo objetivo sobre os processos reflexivos individuais nas propostas teórico-metodológicas de Bernard Lahire, que se dá, em termos gerais, devido à proximidade onto-epistemológica entre Lahire e Bourdieu.

No entanto, ainda que tenhamos uma posição reflexiva sobre isso neste trabalho, também reconhecemos e empregamos a estrutura teórica de Lahire para operacionalizar o conceito de reflexividade, partindo do pressuposto de que os atores sociais se relacionam com suas disposições de múltiplas maneiras. Nesta perspectiva, Lahire defende que os indivíduos têm diferentes graus de reflexividade de acordo com as estruturas contextuais plurais em que interagiram ao longo de suas trajetórias sociais. A suposição de tal pluralidade permite ao pesquisador tratar cada pessoa como um sujeito socializado detentor de uma individualidade que vai além de características como a classe social. Entretanto, tal suposição não considera o indivíduo como completamente autônomo nas interações que ele vive em diferentes esferas sociais (Caetano, 2011, 2012, 2013; Lahire, 2002; Vandenberghe, 2013). Em nossa vida diária, a lógica da prática derivada do senso prático de Bourdieu (Bourdieu, 1991a) e os processos reflexivos acontecem em articulação sistemática e contínua. Portanto, não é possível afirmar que as pessoas agiriam unicamente guiadas por costumes ou rotinas, nem seria plausível considerar que os atores viveriam orientados por escolhas plenamente racionais (Caetano, 2012).

Neste sentido, Lahire $(2002,2006,2015)$ afirma que os atores sociais não abandonam suas condições de agentes constituídos por condições sociais e históricas. Logo, os processos de socialização são essenciais para nós porque permitem a incorporação progressiva de estruturas sociais na forma de esquemas de disposições, ou seja, modos de pensar, agir e sentir. Dialeticamente, tais esquemas são preponderantes na forma como os indivíduos conferem significado e co-constroem o próprio espaço social. 
No entanto, o autor também é crítico sobre a influência de Bourdieu em sua própria obra (Vandenberghe, 2013). Por exemplo, Lahire considera o ator plural como um derivado de diversas influências, sujeito a uma sociedade com intensa diferenciação interna. Elementos como o desenvolvimento da indústria cultural, e a maior divisão social do trabalho oferecem instâncias socializantes cada vez mais heterogêneas, de modo que os indivíduos internalizariam um estoque de disposições igualmente heterogêneas. Neste sentido, a maior ou menor coerência interna de um ator estaria relacionada a um conjunto historicamente inconstante de diferentes forças socializadoras (Lahire, 2002, 2012).

Além disso, a multiplicidade de matrizes de socialização torna impossível estabelecer a prioridade ontológica de um contexto em relação a outros. Assim, as ações individuais são construídas precisamente pela diversidade de experiências sociais às quais as pessoas são submetidas. Além deste estoque de experiências internalizadas, os atores também ganham um senso prático e capacidade de reflexão que lhes permite ter algum grau de consciência sobre a adequação e relevância de seus esquemas de disposições quando inseridos em estruturas contextuais específicas (Lahire, 2015; Vandenberghe, 2013).

Como resultado dessas elucubrações, a noção de sentido prático de Lahire difere conceitualmente da bourdieusiana (Caetano, 2012). Por um lado, as duas noções são semelhantes, pois ambas são o produto de trajetórias de aprendizagem que acabam tornando as práticas espontâneas, naturalizando-as em nossa vida social. Elas também assumem que as práticas ocorrem tanto como um modo de ação pré-reflexivo quanto semiconsciente (Bourdieu, 1991a, 1991b). Por outro lado, Lahire (2004, 2005) confronta a ideia de tal ajuste pré-reflexivo aos contextos, demonstrando empiricamente que no uso da escrita, por exemplo, existem funções mnemônicas, organizadoras, de planejamento e reflexivas que rompem com o senso prático. Há todo um conjunto de práticas que vão além das ações pré-reflexivas, ou seja, tais práticas foram consideradas, fundamentadas e controladas no decorrer das vidas das pessoas.

Não obstante a relevância das contribuições de Lahire, Caetano (2013) destaca uma lacuna pertinente nas teorizações do sociólogo. Apesar de Lahire admitir que os agentes sociais são atores plurais, eles o seriam devido aos efeitos sociais e históricos de suas socializações passadas mais a amplitude das que ocorrem no presente, juntamente com a lógica da prática que permeia suas biografias. Em outras palavras, quanto mais as socializações dos indivíduos são plurais, mais heterogêneos estes atores sociais tendem a ser. A questão emergente é que tais atores se definem principalmente pelas condições materiais de possibilidade provenientes dos diferentes contextos sociais nos quais foram formados. Levando esta crítica aos seus limites, não haveria nada interno às pessoas que não pudesse ser procurado e explicado externamente.

Apesar da relevância da problematização de Caetano (2013), este peso objetivista é justificável no programa de pesquisa de Lahire. Ao enfatizar o poder duradouro dos processos de socialização através do estudo das trajetórias sociais, Lahire busca a compreensão de como e por que os atores tomam decisões e vivem suas vidas. Além disso, ao remontar a metáfora do mundo social dobrado em indivíduos, Lahire engloba os distintos campos sociais e posições presentes dentro dos próprios atores. Portanto, as crises que levam à reflexividade tendem a ser mais comuns em suas obras do que nas de Bourdieu, uma vez que a lógica agonística dos campos sociais se instala dentro das pessoas (Vandenberghe, 2013).

Para compreender as capacidades reflexivas dos indivíduos, é preciso também compreender suas condições materiais de existência e é aí que as ferramentas interpretativas de Lahire provam ser contributivas (Lahire, 1997, 2002, 2004). Por exemplo, a noção de contextos de interação (ou estruturas contextuais) permite integrar aspectos externos aos comportamentos dos agentes, que também são possibilitados por suas posições no espaço social. Além disso, estes contextos dão lugar a diferentes níveis de reflexão e é também no curso das interações sociais que os indivíduos podem refletir, com a presença de outros, sobre problemas, objetivos, planos e intenções, elucidando suas próprias possibilidades e limitações (Caetano, 2013). Ademais, a interconexão entre fatores sociais e reflexividade tem um duplo significado. Primeiro, considera os efeitos que os recursos e os contextos têm sobre a forma como os indivíduos se veem. Em segundo lugar, leva em conta a eficácia causal da reflexividade nas estruturas contextuais e nas condições materiais de existência (Caetano, 2012).

Subjacente a tal interconexão, existe também uma dimensão temporal. Na medida em que a capacidade de reflexão de cada pessoa se refere a circunstâncias externas, ela também variará de forma distinta de acordo com as estruturas contextuais vividas no tempo presente. Neste sentido, o trabalho de Lahire ajuda a lembrar que as situações de crise com o significado prático mais frequente na vida cotidiana não são apenas estruturais. Portanto, quanto mais um ator se envolve em uma prática em um contexto particular, mais provável que ele se distancie e reflita sobre ela (Caetano, 2013; Lahire, 1997, 2002, 2004).

Como forma de proporcionar uma compreensão empírica a implicações analíticas e reconhecer o potencial epistemológico proveniente destes aparatos conceituais, apresentamos o caso de José Francisco Bernardes Milanez, ativista ambiental histórico e, no período de escrita deste artigo, presidente da Associação Gaúcha de Proteção ao Ambiente Natural (Agapan). 


\section{METODOLOGIA}

Em uma biografia sociológica como a aqui apresentada, na mesma medida que uma análise sociológica em nível individual, as disposições de um sujeito são inferidas com base nos fatos que sustentam a trajetória do ator social tal como ela foi narrada. Uma vez que nenhuma narrativa é constituída sem ter uma perspectiva específica, mas sim processos sociais, o pesquisador precisa ser parcimonioso na reconstrução da narrativa autobiográfica, pois é comum que o biografado projete uma versão mais coerente de si mesmo, criando o fenômeno que Bourdieu (2005) chamou de ilusão biográfica. Tal fenômeno pode ser testemunhado, por exemplo, na atenção diferenciada que a pessoa dá a um determinado contexto ou na ênfase que dá a um conjunto específico de eventos coerentes. É assim que o entrevistado fomenta os elementos que melhor retratam sua versão "favorita" de si mesmo (Coutinho, 2015; Lahire, 2010; Lima, 2015).

Na realização de entrevistas, a consciência acerca dessas questões foi seminal para evitar dois erros metodológicos. Primeiro, no decorrer da entrevista, o pesquisador não conectou as perguntas e descrições que o entrevistado fez, nem se apegou a seleções e situações. A respeito disso, o pesquisador fez perguntas abertas às quais o entrevistado não teve necessariamente respostas rápidas, pois estas perguntas forneceriam o melhor material para uma construção verdadeiramente sociológica, uma vez que incorporariam melhor o princípio de que os atores sociais nem sempre estão conscientes dos motivos que condicionam suas práticas. Em segundo lugar, durante a análise, era imperativo prestar muita atenção aos traços das disposições nos processos que poderiam ser extraídos de momentos importantes da entrevista, que os próprios atores em sua maioria ignoram. Como o entrevistado poderia não ser capaz de assumir que nem sempre esteve ciente de suas motivações, o cientista social se esforçou para adquirir algum excedente de visão, o que lhe permitiu analisar as informações além dos elementos que o ator realmente conhece (Lahire, 2004, 2010). Consequentemente, as entrevistas não estruturadas se basearam em perguntas abertas, que não seguiram uma estrutura previamente concebida, mas sim perguntas sobre e considerando os processos baseados em relatos sobre a infância/adolescência do entrevistado, sua trajetória escolar/ acadêmica, sua vida profissional ou sua carreira política, dependendo do caminho narrativo que ele desejava seguir e seguindo uma abordagem semelhante à empregada por Coutinho (2015) e Lima (2015).

Além disso, visando identificar variações sincrônicas e diacrônicas de disposições, uma parte importante de cada entrevista foi dedicada a comentar os momentos de crise e mudança, pois estes são considerados os que potencialmente revelam as transformações reflexivas nos estoques de disposições. Mais frequentemente, é quando as condições objetivas de existência mudam, que certas disposições podem ser atualizadas (Lahire, 2004).

Ademais, seguindo as possibilidades de coleta de dados em pesquisas qualitativas interpretativistas, a operacionalização e consequente construção desta biografia sociológica também recorreu ao uso de documentos (Stake, 2011). Segundo o autor, quando aplicada a estudos qualitativos, a pesquisa documental tem o poder de fornecer complementaridade às informações que os entrevistados dão sobre si mesmos, portanto, são essenciais para a elaboração de uma investigação de qualidade. Além disso, tal complementaridade fornece maior legitimidade, validade e riqueza à própria análise.

Portanto, de acordo com esta perspectiva, fontes como fotos, artigos de jornal, vídeos sobre as atividades do biografado e alguns de seus documentos pessoais também foram empregados. Esta pesquisa documental, que se mostrou fundamental, ocorreu organicamente, pois foi considerada metodologicamente vinculada às lentes teóricas subjacentes a esta pesquisa (Stake, 2011).

O processo de pesquisa começou em junho de 2017, quando começou a ser desenhada a possibilidade de fazer a biografia de Milanez. Como mencionado em outras seções, Milanez foi escolhido não apenas por sua singular trajetória e importância no movimento ambientalista brasileiro, mas também por seu papel na Agapan, onde atuou como presidente em diferentes termos e sempre foi um militante próximo. Todo o processo de pesquisa durou dois anos, tendo sido concluído por volta de junho de 2019, tendo sido fruto de inúmeras conversas informais, reuniões, eventos acadêmicos e não acadêmicos.

Além disso, os momentos críticos e as consequentes transformações nas ações disposicionais foram considerados como dotados de uma instrumentalidade que, por sua vez, permitiu a identificação de variações diacrônicas nessas ações. Deste ponto de vista, outra estratégia foi perguntar ao entrevistado em que situações ele acreditava não ter se comportado de acordo com os padrões gerais com os quais ele normalmente se alinhava. Perguntar em que situações uma pessoa não se comporta de forma coerente com seus comportamentos mais idiossincráticos, se oferece a possibilidade de desestabilizar o curso "normal" da entrevista, permitindo assim a identificação dos contextos em que o ator sustentou disposições contraditórias (Coutinho, 2015; Lima, 2015). 
Ademais, deve ficar claro que a densidade e a extensão de uma biografia sociológica não têm nenhuma relação com a ilusão ingênua de que a história de vida de um ator pode ser esgotada em detalhes descritivos (Bourdieu, 2004). No entanto, uma biografia sociológica não é um método sem limitações, já que, como um retrato sociológico, contém as mesmas restrições de qualquer narrativa, o que significa que ela é sempre refém da perspectiva a partir da qual foi reconstruída (Lahire, 2010).

\section{A TRAJETÓRIA REFLEXIVA DE FRANCISCO MILANEZ}

Esta análise traz à luz os elementos reflexivos da trajetória de Francisco Milanez, empregando os aparatos teórico-metodológicos apresentados até o momento. Para tanto, pretendemos cruzar os elementos macro e microssociológicos, ou seja, as estruturas objetivas, subjetivas e os processos reflexivos que constituem as trajetórias biográficas dos indivíduos (ex. Coutinho, 2015; Elias, 1995; Lahire, 2010; Setton, 2015).

Dessa forma, começamos enfatizando que a trajetória de Milanez está entrelaçada por eixos centrais específicos de socialização com pesos distintos em momentos diferentes (Lima, 2015). Neste sentido, é patente que a vida familiar, a escola, o mundo formal do trabalho, sua militância política e seu ativismo ambiental estão enredados e são indivisíveis em sua trajetória, sendo impossível escrever exclusivamente sobre um sem tocar o outro. Além disso, o pano de fundo da trajetória de Milanez denota suas posições nos espaços sociais onde ocorreram as socializações relacionadas, as pessoas que participaram destes processos assim como os relatos que permitiram que eventos aparentemente contingentes fossem unidos em uma narrativa coerente.

Na trajetória de Milanez, as articulações que dão um certo grau de coerência a sua biografia são resultado da conciliação reflexiva proveniente de processos que ocorrem em estruturas contextuais específicas. Neste sentido, estes processos reflexivos mediam a coesão e adequação entre estruturas estruturadas e estruturantes e sua capacidade individual de agência.

Ademais, uma característica importante na biografia de Milanez é sua classe social, que também se entrelaça com os outros elementos mencionados acima. Correspondentemente, esta categoria também é relevante, pois afetou as práticas que Milanez empreendeu ao longo de sua vida e influenciou suas escolhas, seja de forma abertamente consciente ou não. Para Bourdieu (2007), a influência da classe é significativa porque esta categoria opera como mediador, moldando os interesses individuais de ordem material. Tal mediação conecta as práticas dos indivíduos, o contexto econômico histórico mais amplo e os eventos que impactaram diretamente em suas vidas. Além disso, a classe social ainda aparece nos estudos bourdieusianos contemporâneos como um fator importante influenciando as ações das pessoas, tais como suas práticas religiosas e resultados educacionais (por exemplo, Alves, 2016; McKinnon, 2017; Stahl, 2016).

Em uma tentativa preliminar, pode-se descrever a trajetória de Francisco Milanez ao se afirmar que ele nasceu em Porto Alegre em 1956 e é o filho mais novo de uma família de classe média de cinco filhos, composta por seu irmão mais velho, o primogênito, e as três irmãs que precedem Milanez. Seus pais já faleceram, assim como seu irmão mais velho e uma de suas irmãs. Pode-se também apresentar sua vida, ressaltando o fato dele ter dois filhos de seu primeiro casamento, três netos e viver com sua atual companheira em Porto Alegre. Embora pareça uma descrição apropriada quando colocada desta forma linear, esta maneira narrativa se afastaria muito da análise da reflexividade. Se escrita de forma tão linear, a trajetória de Francisco exibiria uma coerência homogeneizadora que não seria sustentada quando fossem analisados os processos reflexivos essenciais para a atualização de suas disposições, que reverberam recursivamente em sua trajetória biográfica. Além disso, esses processos são fundamentais, pois foram eles que lhe permitiram integrar instâncias objetivas e subjetivas de sua vida social.

Como Lahire $(1997,2005,2015)$ enfatiza, os contextos de socialização são plurais, heterogêneos e têm um peso estrutural na delineação individual das trajetórias. No entanto, este fenômeno não ocorre mecanicamente. Esta afirmação pode ser observada na vida de Francisco quando, por exemplo, a morte de seu pai em 1967, quando Milanez tinha 11 anos de idade, o impulsionou para uma série de socializações típicas de adolescentes mais velhos ou mesmo homens adultos. A morte do chefe de família tornou-se uma problemática matricial (Lahire, 2010) com repercussões diferentes não apenas em suas responsabilidades, mas também nas de sua mãe, irmão e irmãs mais velhos. Correspondentemente, houve processos reflexivos cruciais nesse momento, pois Milanez gradualmente deixou a posição de filho mais novo para começar a ocupar também outra, ou seja, a de segunda figura masculina mais importante da família, ocupando relativamente as responsabilidades relacionadas a essa posição. 
Neste sentido, o momento de crise gerado pela morte de seu pai induziu os papéis de cada membro da família a mudarem sistemática e dinamicamente, exigindo esforços reflexivos constantes que, por sua vez, reconfiguraram a sociabilidade interna da família e afetaram aqueles que os rodeavam. Em outras palavras, o papel de cada um na estrutura familiar de classe média não mudou linearmente, por exemplo, com o filho mais velho assumindo as funções que pertenciam ao falecido pai. Essas funções (por exemplo, provedor familiar e estabelecimento de certas regras) foram fragmentadas entre os membros da família em certa medida, sendo exercidas de maneiras diferentes em temporalidades distintas por cada um deles.

No entanto, a reflexividade mediadora dessas tomadas de posição foi fundamentada, como assinala Lahire, por processos relacionais estabelecidos inseparavelmente da forma como esses indivíduos interagiam com as estruturas sociais maiores, assim como foram sustentados pela temporalidade e pelas posições que esses indivíduos ocupavam no espaço social (Lahire, 1997, 2002, 2004). Por exemplo, os processos reflexivos que afetaram as trajetórias políticas e acadêmicas de Milanez foram influenciados de forma relacional pelas experiências vividas durante o período de vida de seu pai. Segundo os relatos de Milanez, embora seu pai fosse um homem com uma mentalidade tradicional, ele defendia ideias progressistas como redução de desigualdades e o fortalecimento de redes de assistência social. Ideias que Milanez também defendeu ao longo de sua biografia, seja como líder político ou como pesquisador.

O conjunto de socializações geradas por este evento crítico levou Francisco a outras séries de experiências ligadas a aproximações e desprendimentos de figuras de autoridade no decorrer de sua vida escolar. Além disso, as socializações de Milanez começaram a caminhar para um envolvimento político mais direto, fato que ressoa em sua socialização com seu pai, que tinha tido uma vida pública e tinha sido conhecido entre algumas figuras políticas de sua cidade natal, Canoas. Ademais, a trajetória de Francisco tem sido continuamente articulada com um grau de militância política, que também tem sido sistematicamente entrelaçada por preocupações relacionadas à proteção ambiental.

O entrelaçamento entre as estruturas contextuais e a temporalidade pode ser objetivado ao se relatar que Milanez ingressou na Agapan quando ele tinha apenas quinze anos de idade, e a própria Associação havia sido fundada em 1971 por José Lutzenberger ${ }^{2}$ e outros ambientalistas. Milanez tem sido um ativista da organização desde então, ele foi seu presidente nos anos 90, a década na qual também iniciou sua militância política formalizada mediada por sua filiação ao Partido dos Trabalhadores (PT). Quanto ao seu cargo de presidente da Agapan, ele o ocupou de 2011 a 2013 e, em 2017, foi eleito novamente, cargo que ocupou até junho de 2019.

As disposições e os processos reflexivos articulados a partir das experiências com o movimento ambiental são fundamentais para compreender as escolhas acadêmicas feitas por Milanez. Na época de seus estudos universitários, ele também aproveitou a oportunidade para ingressar no movimento estudantil da Universidade Federal do Rio Grande do Sul, trazendo para a agenda de sua militância parte do ativismo que ele havia desenvolvido na causa ambiental. Quanto às suas escolhas acadêmicas, assim como a relação entre estas escolhas e suas disposições, elas se relacionam objetivamente na trajetória de Milanez com o fato de ter se formado em Arquitetura em 1983 e em Biologia em 1985, ambas graduações cursadas na Universidade Federal do Rio Grande do Sul, onde também obteve o mestrado em Educação Científica, passando depois para o doutorado na mesma área. Os processos reflexivos que o levaram a estas escolhas são inseparáveis das disposições e competências de ensino que Milanez vinha mobilizando desde a adolescência, quando se tornou tutor particular para disciplinas como Química e Matemática. Este trabalho como tutor fazia parte de uma estratégia para, após a morte de seu pai, tornar-se mais financeiramente independente de sua família.

Assim, embora pareçam aleatórias ou mesmo contraditórias, estas escolhas foram reflexivamente alinhadas com a coesão e coerência atribuídas a Milanez como ator social, ou seja, alguém que está ligado ao mundo das ciências naturais e causas ambientais, mas tem uma rede de relacionamentos construída sobre uma intensa vida política. Seguindo a conjugação de estruturas, agência individual e processos reflexivos, a trajetória de Milanez se baseia nesses elementos para reconfigurar e atualizar seu conjunto de disposições, na medida em que as atuais estruturas contextuais que ele vive mudam dinamicamente. Existem de fato estruturas sociais que condicionam suas possibilidades, mas deixam espaço para sua agência pessoal e a mediação entre estas duas instâncias acontece através do exercício de suas capacidades reflexivas. Por exemplo, estas capacidades foram expressas na articulação entre suas práticas, suas experiências passadas e sua posição de classe social,

${ }^{2}$ José Lutzenberger (1926-2002) was a well-known Brazilian environmentalist, being one of pioneers in the struggles against the use of pesticides and for the defense of the Amazon Forest. After a thirteen-year career in a chemical company, Lutzenberger changed his trajectory in 1971 and along with other environmentalists founded Agapan. He was its first president and occupied the position until 1983 (Dreyer, 2004$).$ 
influenciadas pelo contexto da época, sendo essenciais para suas escolhas acadêmicas, bem como para a trajetória política consideravelmente coerente que ele vem liderando. Nesta perspectiva, estes contextos de sua vida foram integrados por práticas ligadas à preservação do meio ambiente natural, à agroecologia e à redução das desigualdades sociais.

A participação política de Francisco ocorreu principalmente através dos movimentos estudantis e da Agapan no período anterior à redemocratização brasileira em 1985, mas, posteriormente, esta participação começou a ocorrer através de um partido político (o Partido dos Trabalhadores) como instituições e estruturas democráticas desenvolvidas ao longo do tempo. Nos anos 90, por exemplo, ele ingressou no partido e foi candidato a prefeito de Canoas, uma cidade da região metropolitana, em 1992. Além disso, ele foi assessor ambiental do prefeito Raul Pont em Porto Alegre de 1997 a 2000, acumulando as funções de coordenador do Programa Guaíba Vive, uma iniciativa para proteger o rio da cidade, e na Comissão Interinstitucional de Planejamento da Orla Marítima de Porto Alegre. Analiticamente, este conjunto de eventos não só expressam a formalização e mediação que as socializações no partido político tiveram na trajetória de Milanez, mas também podem ser interpretados como resultado direto do processo de redemocratização que estava se consolidando no Brasil. Mais uma vez, a estrutura contextual e as possibilidades de agência individual são dialéticas, mas é possível argumentar que a primeira precedeu as escolhas emergentes na segunda, articuladas com seu estoque de disposições e os processos reflexivos necessários para adaptar sua realidade objetiva às suas expectativas e vontades subjetivas.

Portanto, os processos reflexivos de Francisco foram essenciais para reconciliar as contradições emergentes em suas socializações, surgindo nos mais diversos quadros contextuais. A partir desta perspectiva, em uma representação revelando suas próprias impressões de si mesmo, Milanez relatou que, embora tenha nascido em uma família de classe média que qualificou como politicamente conservadora, ter estudado em escolas de classe média alta, e se tornado um homem de negócios (ocupando uma posição de representação substantiva em uma das principais associações desta classe no final dos anos 80); desde sua adolescência, no entanto, ele também manteve uma inclinação patente para ideias políticas relacionadas com a esquerda brasileira.

Como tal, ele articulou diferentes posições, bem como tomadas de posição em movimentos e organizações sociais que seguem uma matriz ideológica progressiva no Rio Grande do Sul. Os confrontos e lutas em contextos distintos e com pessoas com disposições opostas às suas, o levaram a refletir e mobilizar práticas específicas, que pareciam as mais adequadas ao contexto em que ele se encontrava em um determinado momento. Além disso, de acordo com os relatos de Milanez e com os documentos que forneceu, o capital social que acumulou lhe permitiu se engajar e ter sucesso em diferentes empreendimentos, como o caminho positivo que ele tem sido capaz de trilhar no movimento agroecológico. Neste sentido, seus processos reflexivos, assim como as ações por eles geradas, também foram possíveis devido a elementos passados e estruturais de sua vida social mediados por sua posição de classe social, o contexto histórico e as estruturas sociais relacionadas.

Como um esforço complementar de síntese teórico-empírica, é importante ressaltar que esta análise avança e contribui ao estabelecer uma relação dialética entre os aparatos conceituais dois autores franceses, para avançar na análise e compreensão do papel dos estoques de disposições individuais no desenvolvimento das práticas particulares que ocorrem em diferentes contextos de ação. A este respeito, esta contribuição afirma a heterogeneidade desses estoques de disposições. Ela também enfatiza que os indivíduos são atores plurais que passam por suas trajetórias por diferentes contextos de ação, assim, na medida em que são plurais e socialmente heterogêneos, os indivíduos desenvolvem disposições que também são heterogêneas tanto em termos inter como intradisposicionais. Por fim, esta contribuição aponta para a interface entre as perspectivas macro e microssociológicas, promulgadas de forma complementar entre si. 


\section{CONSIDERAÇÕES FINAIS}

Este trabalho se concentrou em fornecer observações teóricas e empíricas sobre como o conceito de reflexividade pode ser compreendido na sociologia de Pierre Bourdieu, bem como sobre a forma como reverberou e foi desenvolvido na sociologia a nível individual de Bernard Lahire. No momento empírico, nossos esforços foram para fazer a articulação analítica entre o aparato epistemo-teórico-metodológico dos dois autores e parte da trajetória biográfica de José Francisco Bernardes Milanez, que foi escolhido por ser um ator de destaque no movimento ambiental brasileiro.

$\mathrm{O}$ argumento aqui apresentado foi que o conceito de reflexividade de Bourdieu tem uma faceta bastante objetivista, que em última instância delega um status secundário à agência individual e às capacidades reflexivas. Entretanto, estas capacidades podem ser mais bem compreendidas e investigadas considerando as formas pelas quais os indivíduos mobilizam dialética e concomitantemente seus processos reflexivos com suas práticas cotidianas. Para entender este segundo argumento, que pode ser visto empiricamente na trajetória de Milanez, demos centralidade à forma como Bernard Lahire critica e avança com a maneira como Bourdieu delimita as possibilidades reflexivas dos atores sociais.

Além disso, é importante destacar que tanto para a produção desta pesquisa quanto para suas conclusões, os estudos sociológicos em geral podem ser iminentemente mais substantivos se considerarem estrutura, agência e reflexividade de forma integrada, movimento permitido pela agregação de elementos conceituais e argumentativos desses dois autores. Assim, a proposta aqui apresentada contribui para um avanço em direção à fuga da falsa antinomia entre estrutura e agência que eventualmente aparece nas ciências sociais teóricas e aplicadas. A trajetória de Milanez torna explícito que estrutura, agência e reflexividade são elementos inseparáveis e atuam em relação um ao outro.

Inicialmente enfatizamos a importância das construções teóricas de Bourdieu, quando foi necessário trazer à tona a gravidade social das estruturas sobre as práticas individuais. Deste ponto de vista, a forma como as socializações se estabelecem na historicidade das experiências individuais são incorporadas e levadas pelos agentes, sendo constantemente atualizadas em um processo permanente. As relações históricas inculcadas na matriz de esquemas mentais de percepção, avaliação e ação continuam pesando no mundo social, mas tal matriz não é estática, mecânica e imutável.

Esta forma de conceber o habitus foi ainda mais questionada e reformulada por Bernard Lahire quando ele observou as práticas diárias dos indivíduos. $O$ autor revelou que o habitus não é uma matriz ou um conjunto, mas sim um estoque de disposições, o resultado dialético das interações com os mais variados atores sociais e estruturas contextuais que inevitavelmente encontramos ao longo de nossas trajetórias biográficas. Além disso, consideramos que tal interpretação aqui tende a dar mais destaque ao peso das estruturas em relação à agência individual, e pode eventualmente dar um papel secundário às capacidades reflexivas que as pessoas têm, que são dotadas, até certo ponto, pela forma como essas capacidades são praticamente articuladas. No entanto, cabe também ao cientista exercer uma vigilância epistemológica no sentido de avançar analiticamente com estes aparatos conceituais, prestando atenção às evidências empíricas que corroboram (ou não) com possíveis suposições teóricas e metodológicas. Seguindo a linha epistemológica defendida tanto por Bourdieu quanto por Lahire, a teoria não pode servir como um impasse para análises e interpretações.

Em conclusão, as Ciências Sociais Aplicadas são campos vivos e pungentes. Portanto, tem muito a ganhar resgatando e se concentrando nas discussões reflexivas apesar de algumas falsas antinomias que ainda perduram nos debates acadêmicos e procedimentos analíticos. Para tanto, torna-se imperativo discutir ferramentas teóricas e metodológicas que permitam a investigação aprofundada dos mais diversos processos reflexivos e suas dinâmicas. Podemos fazê-lo estudando, problematizando e escrevendo com e contra epistemologias e autores clássicos e contemporâneos, abordando ou distanciando potenciais contribuições sempre que possível. 


\section{REFERÊNCIAS}

Alves, A. R. C. (2016). Dos habitus de classe aos patrimônios individuais de disposições: reflexões sobre a prática em Pierre Bourdieu e Bernard Lahire. Sociologias, 18(42), 294-327.

Bourdieu, P. (1991a). Language and symbolic power. Cambridge, MA: Harvard University Press.

Bourdieu, P. (1991b). The logic of practice. Cambridge, MA: Harvard University Press.

Bourdieu, P. (2004a). Os usos sociais da ciência: por uma sociologia clínica do campo científico. São Paulo, SP: Unesp.

Bourdieu, P. (2004b). Science of science and reflexivity. London, UK: Polity Press.

Bourdieu, P. (2005). Razões práticas: sobre a teoria da ação. Campinas, SP: Papirus.

Bourdieu, P. (2007). A distinção: crítica social do julgamento. Porto Alegre, RS: Zouk.

Bourdieu, P., \& Wacquant, L. J. D. (1992). An invitation to reflexive sociology. Chicago, IL: Chicago University Press.

Caetano, A. (2011). Para uma análise sociológica da reflexividade individual. Sociologia, Problemas e Práticas, 66, 157-174.

Caetano, A. (2012). A análise da reflexividade individual no quadro de uma teoria disposicionalista. In J. T. Lopes (Org.), Registos do actor plural: Bernard Lahire na sociologia portuguesa (pp. 15-29). Porto, Portugal: Edições Afrontamento.

Caetano, A. (2013). Vidas reflectidas: sentidos, mecanismos e efeitos da reflexividade individual (Tese de Doutorado). Instituto Universitário de Lisboa, Portugal, Lisboa.

Correa, D. S. (2015). Anjos de fuzil: uma etnografia das relações entre tráfico e Igreja na favela Cidade de Deus (Tese de Doutorado). Universidade do Estado do Rio de Janeiro, Rio de Janeiro, RJ.

Coutinho, P. (2015). "Meu sonho era maior que eu": biografia sociológica de uma trânsfuga de classe (Tese de Doutorado). Universidade Estadual do Rio de Janeiro, Rio de Janeiro, RJ.

Crossley, N. (2001). The phenomenological habitus and its construction. Theory and society, 30(1), 81-120.

Dreyer, L. (2004). Sinfonia inacabada: a vida de José Lutzenberger. Porto Alegre, RS: Vidicom Audiovisuais.

Elias, N. (1995). Mozart: sociologia de um gênio. Rio de Janeiro, RJ: Jorge Zahar Ed.
Lahire, B. (1997). Sucesso escolar nos meios populares: as razões do improvável. São Paulo, SP: Editora Ática.

Lahire, B. (2002). O homem plural: os determinantes da ação. Petrópolis, RJ: Vozes.

Lahire, B. (2004). Retratos Sociológicos: Disposição e variações individuais. São Paulo, SP: Artmed.

Lahire, B. (2005). Patrimônios individuais de disposições: para uma sociologia à escala individual. Sociologia, Problemas e Práticas, 49, 11-42.

Lahire, B. (2006). A cultura dos Indivíduos. São Paulo, SP: Ed. Artmed, 2006.

Lahire, B. (2010). Franz Kafka: Éléments pour une théorie de la création littéraire. Paris, France: La Découverte.

Lahire, B., \& Amandio, S. (2012). Do Homem Plural ao Mundo Plural. Análise Social, 202, 195-208.

Lahire, B. (2015). A fabricação social dos indivíduos: quadros, modalidades, tempos e efeitos de socialização. Educação e Pesquisa, 41(spe), 1393-1404.

Lima, P. R. M., Jr. (2013). Evasão do ensino superior de Física segundo a tradição disposicionalista em sociologia da educação (Tese de Doutorado). Universidade Federal do Rio Grande do Sul, Porto Alegre, RS.

McKinnon, A. (2017). Religion and social class: Theory and method after Bourdieu. Sociological Research Online, 22(1), 161-173.

Peters, G. (2013). Habitus, reflexividade e neo-objetivismo na teoria da prática de Pierre Bourdieu. Revista Brasileira de Ciências Sociais, 28(83), 47-71.

Peters, G. (2017a). A ciência como sublimação: o desafio da objetividade na sociologia reflexiva de Pierre Bourdieu. Sociologias, 19(45), 336-369.

Peters, G. (2017b). De volta à Argélia. A encruzilhada etnossociológica de Bourdieu. Tempo Social, 29(1), 275-303.

Setton, M. G. J. (2015). A escolha e o reconhecimento pela educação: o caso de Antônio. Educação e Pesquisa, 41(spe), 1405-1418.

Stahl, G. (2016). Doing Bourdieu justice: thinking with and beyond Bourdieu. British Journal of Sociology of Education, 37(7), 1091-1103.

Stake, R. E. (2011). Pesquisa qualitativa: estudando como as coisas funcionam. Porto Alegre, RS: Penso.

Vandenberghe, F. (2013). A sociologia na escala individual: Margaret Archer e Bernard Lahire. Cadernos do Sociofilo, 4, 70-112. 
Bruno de Souza Lessa

ORCID: http://orcid.org/0000-0002-1696-394X

Doutor em Administração pela Universidade Federal do Rio Grande do Sul (PPGA/UFRGS); Bolsista do Programa Nacional de Pós-Doutorado (PNPD-Capes) da Universidade de Fortaleza (UNIFOR).E-mail: brunolessa85@yahoo.com.br

Fernando Dias Lopes

ORCID: https://orcid.org/0000-0003-0037-0135

Doutor em Administração pela Universidade Federal do Rio Grande do Sul (PPGA/UFRGS); Professor Associado IV da Escola de Administração da UFRGS. E-mail: fernando.lopes@ufrgs.br

Célia Elizabete Caregnato ORCID: https://orcid.org/0000-0002-9326-590X

Doutora em Educação pela Universidade Federal do Rio Grande do Sul (UFRGS); Professora Adjunta da Faculdade de Educação da Universidade Federal do Rio Grande do Sul (UFRGS).E-mail: celia.caregnato@gmail.com 